\title{
Research on the Relationship and Measures of Innovative Ability between Students and Teachers
}

\author{
Suolan Liu and Lizhi Kong \\ Changzhou University, Jiangsu, China, 213164 \\ lan-liu@163.com
}

Keywords: Innovative ability; Students; Teachers; Relationship; Measures

\begin{abstract}
Innovative ability is the ability of introducing new theory, new idea, or inventing new technology and new product. Invention and discovery are the most direct reflection of innovative ability. In this paper, we first analysis innovative ability from academic definition, then discuss the relationship between students and teachers in universities. In order to cultivate students' innovation ability so as to meet the need of social development, we need not only take measures for students but also for teachers. Universities should make great effort to reform the traditional education method, encourage teachers take part in kinds of academic and scientific activities, and build good environment for innovative education.
\end{abstract}

\section{Introduction}

With the fast development of economy, the society has great improving demand for students in many majors, such as science and information. In these areas, competition is very fierce and new technology updates continuously and fast. It expresses sharply and higher requirements for talent, especially talent with great innovation. Therefore, innovation becomes a permanent topic for social development and progress of human being. To ensure a continuous supply of high-level talents with innovative ability, we must continue to promote education innovation, which is the base of students' innovative ability reform. In academic definition, 'innovative ability' can be divided into special talent innovation and self-realization innovation. The former special talent innovation usually can produce new things with social value. It mainly refers to creativity shown by scientists, inventors, artists and other special characters. On the other hand, the latter of self-realization innovation refers to the possibility of development, its creativity in this sense is a kind of creativity with individual activities owned and produced by himself. Everyone has self-realization innovation ability with different levels. Higher Education highlights the self-realization innovation, which is not required all students to achieve the same level in accordance with uniform standards, but to achieve full development for those educated in all development it already have. For university students, innovative ability is a kind of competence that can be improved by learning, thinking, and researching. These measures can help to make new breakthroughs and new outcomes synchronously on the basis of consolidate existing knowledge. From these explanation, we should know innovation is not isolated. It is mainly composed by knowledge, skill, experience, innovative thinking, creative individuality, innovative practice, etc. When cultivate creativity, we should start from the components of innovation in order to facilitate the development of innovation by development of various components.

Changzhou university is a fast developing university and locates in the economically developed Yangtze Delta. Students graduated from our university mainly work in this area. These years, to promote the process of students innovation ability, we have done a series of exploration and attempt to cultivate students, such as teacher's innovative ability, education ideas and ways, and innovation platform construction, and so on. 


\section{Improving Measures for Students' Innovative Ability}

At present, it is still a hot topic of how to guide graduate students to master basic theory, knowledge and skills in their professional field so as to quickly and effectively cultivate the creative thoughts in innovation of current graduate education. To each student, background knowledge should be grasped early, which is helpful to develop their innovative personality and innovative potential. These will guide them to develop their subject and promote research ability. They determine the starting point of research and innovation, arouse the desire to innovate. Modern graduate subject knowledge is relatively broad, interdisciplinary and cross use multidisciplinary knowledge the advantage of the relatively strong, have certain innovation ability.achieve the innovation of the new theory and application with the help of independent innovation research. As cultivating students' innovation consciousness and practical ability is a point of quality-oriented education, the core of quality-oriented education, the priority among priorities of basic education reform, as well as one of the basic tasks in the cross-century education reform. Here we give some measures used in our university to improve students innovative ability in recent years.

Cultivate Students' Innovation Emotion. Innovation emotion is the basic need and original power to improve innovation ability for students themselves. It is the emotion of love for success of innovative business. It's known that the growth of talents contacts with the success of business closely. Bafulerry, a great author ever said that the biggest reward of science is the electricity brought by discovery. Just as most of scientists justified, this is one of the biggest interests in life. It generates strong emotion through discovering new truth and understanding common regulation. It means we can do things activity and the generation of motivation is based on loving activity and pursuing the result of activity, especially the innovative activity. It is impossible to succeed without strong love for the activity. Because the emotion can generate great enthusiasm, which can encourage man do their best to do everything actively. Enthusiasm is the source of power to produce, which may make a man succeed.

Cultivate Students' Creative Personality. Creative personality is integration in thinking and behavior, and has multidimensional structure, contains innovation sense and creative spirit, and it is a kind of attitude and behavioral characteristics which is regularly and different from others, produced in the influenced of some social education. Cultivation of creative consciousness including formation and training in innovation needs, motives, interests, ideals, beliefs. While for creative spirit, it mainly contains formation and development in self-confidence, tenacity, courage, independence, cooperation and other psychological qualities.

Training Students' Innovative Thinking. Sow a thought, reap an action. One of the most important features of innovative ability is the ability of using knowledge flexibly, i.e. they have very strong innovative thinking. Great knowledge can be transformed into capabilities and new results generated in specific practice lying in innovative thinking. Innovative thinking is composed by logical thinking and non-logical thinking. Cultivation of thinking ability in these two aspects both should be cared. Close contact exists between inspiration in science and non-logical thinking. So fully regard is needed both in logical and non-logical thinking in the process of training students' innovative ability.

Encourage Students Participating in Innovative Practice. To realize innovation activities for individuals, we should make vision into reality through practical activities. Express the idea by certain tools, such as using language. Development of students' knowledge absorption and creativity ability will eventually be tested through practice. Therefore, practice especially in creation is one of the most important means and bridges for training students' creative thinking, creative skills and achieve creative goals. These are important parts for cultivating creativity ability.

\section{Improving Measures for Teachers' Innovative Ability}

'For every fresh and clever brain, once it is received education just as a standard part producing, which will be uniform in thinking but lack of individuality and creativity'. In order to cultivate 
students' innovative quality, it is necessary to cultivate teachers' innovative consciousness and ability. Because teachers' innovative spirit and idea have great effect on students' innovative ability. However, in the process of education we commonly only pay attention to the training of students' thinking and mining students' potential ability. We do not aware that teacher's innovation idea, innovation thinking and ability have great relation to the innovation talents cultivation work in universities. This phenomenon can be explained as water without a source and a tree without roots. According to our survey and conclusion, we list several key measures to improve teachers' innovative consciousness and ability.

Encourage Teachers to Take Part in Academic Training Courses and Activities. To strengthen the students innovative ability, we need to expand their scientific horizon and sensitivity to issues at the forefront of science and information, so we should continuously encourage teacher to take part in related training courses especially transfer teachers to go abroad for further study. In recent five years, about over $50 \%$ of the teachers in our department have received different kinds of training in professional, and transport 3 to 5 teachers to USA, Britain, Hongkong, etc. to study abroad every year. By these measures as well as academic exchanging, we not only widen teachers' vision but also build a stable foundation for cultivating innovation talents.

Encourage Teachers to Work in Enterprises. Through participating in enterprise engineering project or research and development projects, teachers obtain more abundant experience of engineering practice. At present, $80 \%$ of the professional teachers have related background experience. Encourage those who have innovative ability and innovative consciousness in enterprises to teach in colleges and universities will fresh new vigor into our class teaching.

Encourage Teachers to Build Scientific Team and Do Research Projects. Strengthen and encourage teacher to build scientific team and apply for scientific research projects positively and provide convenient conditions for teachers carrying out them, which is helpful to improve the level of innovative ability cultivating. Relying on the innovation platform, teacher's innovation practice ability can be enhanced quickly in scientific research work. Also teachers are encouraged to introduce their scientific research achievements into class to promote the transformation of scientific research to teaching practice.

Strengthen the Establishment of the Teacher Evaluation System. At present, the evaluation result is one of the important indicators reflecting a teacher's teaching ability. Therefore, how to build a sound and effective evaluation system is a key role for university leaders. In the evaluation system, we must give consideration to both teaching and scientific research to promote teachers to balance them and realize the transplantation from scientific and technological innovative ability to innovation talents cultivation ability. Establish effective system and give priority to these teachers' title assessment to stimulate the teachers who are innovative and have obtained certain achievement continue to blaze new trails to cultivate more innovation talents with more passion and enthusiasm.

\section{Some Other Suggested Measures}

As we know, the key of training students innovative ability is to pay attention to cultivate students ability to solve practical problems. However, the traditional teaching mode is usually teacher speaking and students listening in classroom. In order to develop the students' ability of innovation, we need to stretch the limited class time to the extra-curricular and create a second classroom. However, the extension of the class time not only requires teachers to have strong business ability, but also needs great sense of responsibility and dedication. Therefore, colleges and universities should be equipped teachers with high comprehensive quality and strong business ability. To solve this problem, we must increase large high-level personnel of the introduction of intensity. At the same time, we can employ some engineers from enterprises and research institute, who have strong practical experience and skills as students practice training guidance teaches. All these measures can help to improve students' innovation ability as well as teachers ability. 


\section{Conclusion}

In China, university education is gradually shifting from elite education to mass education. The amount of college graduates increases rapidly, in order to improve competitiveness in the fierce competition, the cultivation of innovative ability is of very importance. By survey and analysis, we find that there is close relationship between teachers' innovative ability and students' innovative ability. So in this paper we introduce the exploration and practice of science and information major students' and teachers innovation ability cultivation in our university. Kinds of honors and evaluation from employing units during the past few years show that students' innovative ability has been promoted effectively.

\section{Acknowledgments}

This work is supported by the project of Changzhou university (No.2015XSJ11) and project of Changzhou science and education town (No.CDGZ2016002)

\section{References}

[1] Yue Xia. Some measures on the cultivation of university student's innovative ability[J].China education report, 2014,6-12

[2] Yong Zhang, Jianli Dong, Cunhua Li. Review on Innovative Practice Teaching and Its Quality Evaluation System for Software Engineering Specialty[J]. Advanced Technology in Teaching, 2013, 389-397.

[3] Michille. University teachers' innovative teaching behavior and the relationship between the innovative ability of college students Investigate [J]. Journal of teaching research, 2013, 15-18.

[4] YongLin Huang. University research management policy and system in our country [J]. Journal of education and economy, 2015, 3-8.

[5] Klaus Fichter, SeVerin Beucker. The Evolution of Innovation Communities: Case Studies[J]. Innovation Communities, 2012, 57-226

[6] Wei Ping. Local colleges and universities' young teacher innovation ability development's situation and countermeasure research[J]. Journal of China university of education, 2015:73-76.

[7] Zhang Wei. Theory of teachers' subject innovation quality [J]. Journal of education research, 2011, 39-43.

[8] Li Jinchang, Lin Jialian. Promoting the cultivation of innovative talents through combination of practical teaching and academic competition[J]. Experimental Technology and Management, 2011, 28(11):1-4

[9] Feng Zhenggang. Several issues Concerning innovation Consciousness[J]. Journal of Hunan Economic Management Cadre College, 2002(1):6-1 0.

[10] Cao Pan. Training students practical innovation ability by building a four level discipline competion platform. ICETIS 2013,1008-1011

[11] Bian Fei. Study on countermeasures for cultivation innovation ability for college and university students[J]. ICIMTR 2013, 213-217 